\title{
Coronary patients on dialysis: Coronary artery bypass grafting or percutaneous coronary intervention? A complex question for a complex scenario
}

The number of patients with coronary artery disease (CAD), chronic kidney disease (CKD), and end-stage renal disease requiring dialysis is expected to increase in the next decade. Because of multiple coronary lesions and massive calcifications, coronary revascularization of these subjects is often more difficult and demanding. It is known that long-term survival of patients with CKD is worse than that of patients with normal kidney function after coronary artery bypass grafting $(\mathrm{CABG})$ and percutaneous coronary intervention (PCI). ${ }^{1}$ Furthermore, several studies ${ }^{1-6}$ have reported better midterm and long-term results in patients who underwent CABG compared with patients who underwent PCI. Nevertheless, a gap of knowledge regarding the optimal treatment for myocardial revascularization in this subset of patients is still to be filled. Even the most recent $2018 \mathrm{Eu}-$ ropean guidelines ${ }^{7}$ were unable to update the previous 2014 guidelines ${ }^{8}$ because no evidence has been found in this field so far.

In this issue of the Journal, Gaipov and colleagues 9 present their worthwhile retrospective research examining 971 patients with CKD at the time of myocardial revascularization (582 underwent CABG and 389 underwent PCI) extracted from the US Renal Data System. All patients received the treatment at least 5 years before the initiation of dialysis, and the follow-up was performed from the dialysis to March 2014. The authors observed that during the median 1.5-year follow-up, CABG was associated with a $34 \%$ lower risk or mortality after dialysis initiation compared with PCI. Significantly better results after CABG compared with PCI were reported even in patients who presented with congestive heart failure at the time of treatment. The take-home message of the authors is meaningful: Patients with CAD and advanced CKD should undergo myocardial revascularization by $\mathrm{CABG}$ rather than abandoned.

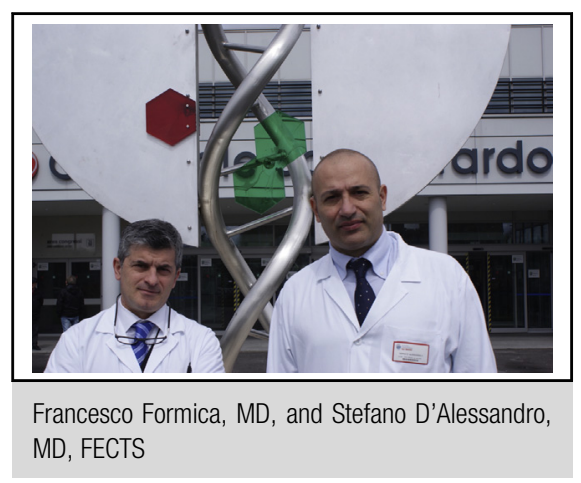

Central Message

In patients on dialysis, those who undergo CABG have better midterm survival than those who undergo PCI. Randomized controlled trials are mandatory to define the role of CABG over PCI in long-term survival.

See Article page 976

PCI because, in case of dialysis, the survival probability of those receiving CABG is significantly better than of those receiving PCI. This message is useful because it could change the attitude of many surgeons who refuse to operate or avoid operating in patients with advanced CKD, who have a higher perioperative risk and a lower life expectancy. However, some aspects should be discussed. In both groups, neither the clinical status at the time of dialysis nor the percentage of patients receiving incomplete coronary revascularization (ICR) is known. It is likely that there is a significant proportion of subjects with ICR due to the frequent severe coronary lesions in patients with CKD. Survival at 1 and 2 years is clearly in favor of CABG. ${ }^{9}$ However, from the third year, the 2 curves presumably tend to be equivalent. Because readers are not aware of the degree of ICR or the clinical status at the beginning of dialysis, it is difficult to know whether CABG is really superior to PCI or whether dialysis per se is a predictor of midterm mortality, regardless of initial treatment.

The best treatment for patients with coronary disease and advanced CKD or end-stage renal disease remains uncertain because there is still an absence of randomized controlled trials. Undeniably, CABG is still primarily used in increasingly complex cases, and this role probably will not be 


\section{References}

1. Milojevic M, Head SJ, Mack MJ, Mohr FW, Morice MC, Dawkins KD, et al. The impact of chronic kidney disease on outcomes following percutaneous coronary intervention versus coronary artery bypass grafting in patients with complex coronary artery disease: five-year follow-up of the SYNTAX trial. EuroIntervention. 2018;14:102-11.

2. Bundhun PK, Bhurtu A, Chen MH. Impact of coronary artery bypass surgery and percutaneous coronary intervention on mortality in patients with chronic kidney disease and on dialysis: a systematic review and meta-analysis. Medicine (Baltimore). 2016;95:e4129.

3. Bangalore S, Guo Y, Samadashvili Z, Blecker S, Xu J, Hannan EL. Revascularization in patients with multivessel coronary artery disease and chronic kidney disease: everolimus-eluting stents versus coronary artery bypass graft surgery. $J$ Am Coll Cardiol. 2015;66:1209-20.

4. Marui A, Kimura T, Nishiwaki N, Mitsudo K, Komiya T, Hanyu M, et al. Percutaneous coronary intervention versus coronary artery bypass grafting in patients with end-stage renal disease requiring dialysis (5-year outcomes of the CREDO-Kyoto PCI/CABG Registry Cohort-2). Am J Cardiol. 2014;114: $555-61$.
5. Terazawa S, Tajima K, Takami Y, Tanaka K, Okada N, Usui A, et al. Early and late outcomes of coronary artery bypass surgery versus percutaneous coronary intervention with drug-eluting stents for dialysis patients. J Card Surg. 2012;27:281-7.

6. Sunagawa G, Komiya T, Tamura N, Sakaguchi G, Kobayashi T, Murashita T. Coronary artery bypass surgery is superior to percutaneous coronary intervention with drug-eluting stents for patients with chronic renal failure on hemodialysis. Ann Thorac Surg. 2010;89:1896-900.

7. Neumann FJ, Sousa-Uva M, Ahlsson A, Alfonso F, Banning AP, Benedetto U, et al. 2018 ESC/EACTS Guidelines on myocardial revascularization. Eur Heart J. August 25, 2018 [Epub ahead of print].

8. Kolh P, Windecker S, Alfonso F, Collet JP, Cremer J, Falk V, et al. 2014 ESC EACTS Guidelines on myocardial revascularization: the Task Force on Myocardial Revascularization of the European Society of Cardiology (ESC) and the European Association for Cardio-Thoracic Surgery (EACTS). Developed with the special contribution of the European Association of Percutaneous Cardiovascular Interventions (EAPCI). Eur J Cardiothorac Surg. 2014;46:517-92.

9. Gaipov A, Molnar MZ, Potukuchi PK, Sumida K, Canada RB, Akbilgic AO, et al. Pre-dialysis coronary revascularization and post-dialysis mortality. J Thorac Cardiovasc Surg. 2019;157:976-83. 